\title{
Study on the Influence of In Situ Stress Distribution on the Stability of Roadway Surrounding Rock
}

\author{
Tao Li $\mathbb{D}^{1,2}$ Hao Gong, ${ }^{1,2}$ and Guoliang Xu $\mathbb{D}^{1}$ \\ ${ }^{1}$ School of Energy and Mining Engineering, China University of Mining and Technology-Beijing, Beijing 100083, China \\ ${ }^{2}$ Department of Resource Engineering, Heilongjiang University of Technology, Jixi 158100, China \\ Correspondence should be addressed to Tao Li; litao5555@126.com
}

Received 10 June 2021; Accepted 7 August 2021; Published 21 August 2021

Academic Editor: Dezhong Kong

Copyright (C) 2021 Tao Li et al. This is an open access article distributed under the Creative Commons Attribution License, which permits unrestricted use, distribution, and reproduction in any medium, provided the original work is properly cited.

In order to understand the instability characteristics of surrounding rock in the process of deep roadway excavation, a threedimensional numerical model was established by FLAC $^{3 \mathrm{D}}$ to systematically analyze the influence of roadway surrounding rock stability under different in situ stress distribution forms, and the environmental coefficient of mining-induced stress $\eta$ was defined, the larger the environmental coefficient of mining-induced stress is, the larger the surrounding rock stress environment is, and the range where the $\eta$ coefficient is greater than 0.2 is called with the destruction-danger zone. When the initial vertical stress is maximum principal stress and minimum principal stress, by comparing the roadway along the middle ground stress direction and minimum or maximum in-situ stress direction, the variation characteristics of displacement, failure zone and failure hazard zone of roadway surrounding rock are obtained, which provides theoretical basis for the treatment of disaster accidents such as roadway surrounding rock instability and rock burst caused by deep high in-situ stress.

\section{Introduction}

All underground engineering activities must be carried out in the earth's crust. Coal mining is to take the crustal rock mass and coal seam as the main research object, so it is extremely important to study the natural properties of underground rock mass and the in situ stress distribution $[1,2]$. In 1912, the concept of geostress was first proposed by Heim, a Swiss geologist [3]. It is pointed out that the rock is in a state of approximate hydrostatic pressure due to the rheological action for a long time under the continuous action of large stress [4-6]. The stress is equal to the gravity of the overlying rock mass, i.e., $\sigma_{x}=\sigma_{y}=\sigma_{z}=\gamma H$. Under hydrostatic pressure, there is no shear stress, and any direction is the principal stress. In 1926, Soviet scholars proposed the following theory [7]: assuming that the rock mass is uniform and continuous elastic medium and according to the theory of elasticity, it is proposed that the vertical stress of the rock mass is equal to the pressure of the rock strata above it, i.e., $\sigma_{v}=\gamma H$. And the horizontal stress $\sigma_{x}=\lambda \gamma H$. For the gravitational field with the ground level, the lateral pressure coefficient $\lambda=\nu /(1-\nu)$, and $\lambda=1$ when the hydrostatic pressure. However, the measured value may be greater than 1.0 or less than 1.0 depending on the area and position of the measured result of $\lambda$ [8-10]. Literature $[11,12]$ showed that the anchor bolt not only provides supporting force on the roadway surface but essentially forms a load-bearing structure with certain strength through the coupling action of anchor bolt and surrounding rock. In literature [13-15], the stress evolution, displacement field, local deformation, overall distribution, and destroy characteristics of surrounding rock anchoring structures were studied with different bolt spacing through model tests. In literature $[16,17]$, the influence of bolt preloading force and bolt spacing on the supporting strength of surrounding rock anchoring structure through numerical simulation software was analyzed, the supporting scheme of excavation roadway was designed, and the effectiveness of the supporting scheme by adopting the roadway displacement measurement scheme was verified. Literature [18-20] showed that under the action of high stress, the two-side coal seam is soft, the stress is uneven, the range of loosening circle is large, and the 
surface deformation shows the characteristics of "two-side displacement amount greater than roof subsidence amount greater than floor heave amount."

With the deepening of coal mining depth in recent years, the original rock stress of underground rock mass is also increasing, and the anisotropy is significant [21, 22]. As a result, the excavation roadway deformation speed is accelerated; roof caving, side deflection, and floor heave are increasingly serious; and the bursting liability is more intense. The number of roadway repair is also increasing correspondingly, and the repair rate of some soft rock roadway has reached more than 90\% [23-25]. Redistribution of in situ stress caused by roadway excavation is closely related to the original rock stress distribution state. In order to accurately grasp the influence of in situ stress distribution on the stability of roadway surrounding rock [26-28], based on the discussion of the distribution form of in situ stress, this paper systematically analyzes the displacement curve of surrounding rock, the range of plastic zone, and the volume of destruction-danger zone to judge the influence on the stability of surrounding rock $[29,30]$.

\section{The Engineering Background and Numerical Model}

2.1. The Engineering Background. This paper takes 7703 bottom pumping roadway in Zouzhuang Mine, Huaibei, Anhui Province, as the engineering background. The construction horizon of the bottom pumping roadway is in sand and mudstone interbed and $16-30 \mathrm{~m}$ away from the coal seam. The lithology is mainly purple piebald mudstone and aluminum mudstone, followed by siltstone and fine sandstone. The occurrence of strata is relatively stable. The direct roof is mudstone, gray to dark gray, massive, with slippery surface, a large number of plant fossil fragments, flat fracture, brittle, fragile, thickness of $1.91 \sim 4.13 \mathrm{~m}$, and average of $3.15 \mathrm{~m}$. The old top is fine siltstone, light gray, fine grain, massive, with thin siltstone bands, a few cracks filled by calcite veins, medium sorting, calcareous cementation, parallel bedding, dense, thickness of $4.10 \sim 90.2 \mathrm{~m}$, and average of $6.12 \mathrm{~m}$. The direct bottom is mudstone, dark gray, argilaceous structure, local silty content is high, relatively dense, flat fracture, a large number of plant rhizome fossils, thickness of $1.02 \sim 3.95 \mathrm{~m}$, and average of $2.39 \mathrm{~m}$. The old bottom is fine silty sandstone, gray, silty structure, the local with high fine sand content, banded, flat and dense fracture, a large number of plant rhizome fossils in the lower part, longitudinal fractures, parallel bedding, thickness of $2.90 \sim 5.61 \mathrm{~m}$, and average of $4.47 \mathrm{~m}$. The comprehensive histogram of roof and floor within the area of working face 7703 is shown in Figure 1.

2.2. The Establishment of Numerical Model. Roadway surrounding rock stability of the numerical model is set up by using FLAC ${ }^{3 \mathrm{D}}$, as shown in Figure 2; the model size is 80 $\mathrm{m} * 60 \mathrm{~m} * 80 \mathrm{~m}$, and the actual depth of the coal seam is $720-800 \mathrm{~m}$. The numerical model includes 9 layers from top to bottom. The sandstone is 11 meters, mudstone is 9 meters,

\begin{tabular}{|c|c|c|c|}
\hline Rock stratum & Histogram & Thickness (m) & Rock character \\
\hline Sandstone & & 11 & $\begin{array}{l}\text { Gray, massive, thick bedded, intercalated with } \\
\text { thin mudstone, gentle wave bedding, dense. }\end{array}$ \\
\hline Mudstone & & 9 & $\begin{array}{l}\text { Light gray, massive, uneven fracture, local } \\
\text { silt, upper siderite oolite, brittle. }\end{array}$ \\
\hline Siltstone & & 7 & $\begin{array}{l}\text { Gray, fine grain, good sorting, siliceous } \\
\text { cementation, hard. }\end{array}$ \\
\hline Glutenite & & 4 & Gray, massive, flat fracture. \\
\hline Mudstone & & 5 & Dark gray, massive, flat fracture. \\
\hline Siltstone & & 4 & Gray, fine grain, good sorting. \\
\hline Mudstone & & 23 & $\begin{array}{l}\text { Massive, thick bedded, locally intercalated } \\
\text { with thin siltstone, gentle wave bedding, with } \\
\text { a small amount of carbonaceous layer, } \\
\text { relatively dense. }\end{array}$ \\
\hline Sandstone & & 5 & Gray, massive, gentle wave bedding, dense. \\
\hline Mudstone & 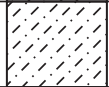 & 12 & $\begin{array}{l}\text { Dark gray, massive, flat fracture, see a large } \\
\text { number of plant fossil fragments, the layer } \\
\text { is carbonaceous, brittle. }\end{array}$ \\
\hline
\end{tabular}

FIgURE 1: Comprehensive histogram of borehole.

siltstone is 7 meters, conglomerate is 4 meters, mudstone is 5 meters, siltstone is 4 meters, mudstone is 23 meters, sandstone is 5 meters, mudstone is 12 meters, respectively, and the cumulative thickness is 80 meters. The dip angle of each rock stratum is $15^{\circ}$. Physical and mechanical parameters of rock strata are shown in Table 1.

Excavation roadway is located in the middle of the model 23 meters mudstone environment, occurrence depth of $760 \mathrm{~m}$; roadway cross section adopts the design of arch section, the section size of 5 meters wide and 4 meters high, along the $Y$ direction for excavation, excavation length of $60 \mathrm{~m}$, model size greater than the roadway section size, thereby eliminating the boundary effect on the result of numerical calculation. The Mohr-Coulomb model is used to simulate the mechanical response characteristics of the surrounding rock mass in the process of excavation. A fixed displacement boundary condition is adopted at the bottom and around the model, and a vertical stress is applied at the top of the model to simulate other overburden strata that have not been built into the numerical model. The step-bystep characteristics of surrounding rock stress, displacement, plastic zone, and failure risk zone caused by roadway excavation are analyzed to evaluate the stability of surrounding rock under the influence of mining.

\section{Influence of In Situ Stress Distribution on the Stability of Roadway Surrounding Rock}

3.1. Influence of In Situ Stress Distribution on Roadway Surrounding Rock Displacement. In order to quantitatively analyze the influence of different forms of in situ stress distribution on the displacement of surrounding rock, a vertical survey line was arranged on the roof and floor of the roadway, respectively, and a horizontal survey line was arranged on the left and right sides of the roadway, respectively. According to the elastic mechanics knowledge, the excavation of the chamber in the undisturbed rock will inevitably cause the redistribution of the original rock stress, resulting in the production of plastic zone (and plastic zone). According to the analytical formula of the Gilch solution, the 


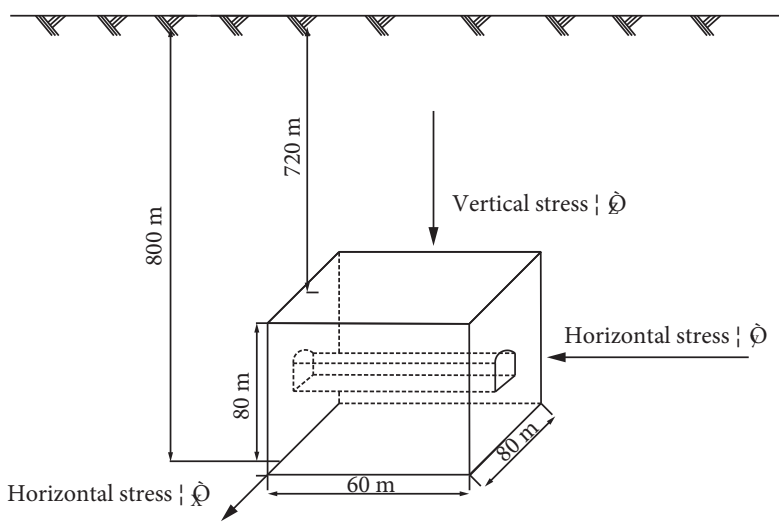

(a)

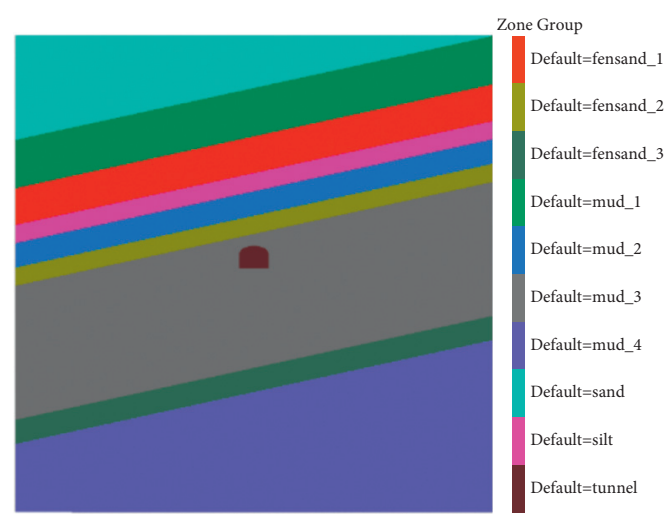

(b)

FIgURE 2: Numerical analysis model of surrounding rock stability of roadway: (a) force analysis diagram; (b) numerical model diagram.

TABle 1: Physical and mechanical parameters of rock strata.

\begin{tabular}{|c|c|c|c|c|}
\hline Rock parameter & Siltstone & Mudstone & Glutenite & Sandstone \\
\hline Bulk modulus (GPa) & 1.11 & 0.83 & 1.0 & 0.97 \\
\hline $\begin{array}{l}\text { Shear } \\
\text { modulus (GPa) }\end{array}$ & 0.83 & 0.38 & 0.6 & 0.72 \\
\hline $\begin{array}{l}\text { Cohesive } \\
\text { forces }(\mathrm{MPa})\end{array}$ & 6.0 & 3.0 & 4.0 & 5.0 \\
\hline $\begin{array}{l}\text { Angle of internal } \\
\text { friction }\left({ }^{\circ}\right)\end{array}$ & 38 & 32 & 34 & 38 \\
\hline $\begin{array}{l}\text { Angle of } \\
\text { dilatancy }\left({ }^{\circ}\right)\end{array}$ & 10 & 10 & 10 & 10 \\
\hline $\begin{array}{l}\text { Tensile } \\
\text { strength }(\mathrm{MPa})\end{array}$ & 2.5 & 1.0 & 1.5 & 2.0 \\
\hline
\end{tabular}

range of the plastic zone is generally $3-5$ times of the length of the chamber rock mass. And the width of the section size in the numerical model is $5 \mathrm{~m}$, so the range of the plastic zone caused by excavation is about $15-25 \mathrm{~m}$. Therefore, the maximum length of $25 \mathrm{~m}$ is adopted here as the analysis area. The numerical model of the roadway surrounding rock cross survey line was established, as shown in Figure 3.

The vertical displacement of the survey line of the top and bottom was extracted and curves were drawn, as shown in Figure 4. When the initial vertical stress is the maximum in situ stress, the deformation degree of surrounding rock is higher when the roadway is tunneling along the middle in situ stress direction than when the roadway is tunneling along the minimum in situ stress direction. Under the condition of hydrostatic pressure, the surface deformation of surrounding rock of roadway is higher than the first two types of in situ stress distribution and deep roadway surrounding rock deformation is lower than the first two types of ground stress. For the above three kinds of in situ stress condition, vertical displacement shows slowly lowering trend from the roadway surface to the deep roadway direction, and surface reduced to 0 about $15 \mathrm{~m}$ away from the roadway. When the initial vertical stress is the minimum in situ stress, the degree of vertical displacement of surrounding rock on the roadway surface is higher than that in the direction of maximum in situ stress when the roadway is excavated along the middle in situ stress direction, and the

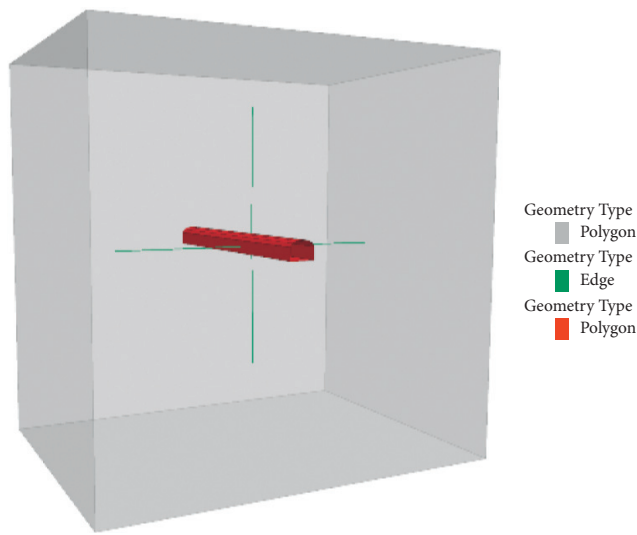

Figure 3: Numerical model of roadway surrounding rock cross survey line.

degree of vertical displacement of surrounding rock on the roadway surface is smaller than that in the case of tunneling along the maximum in situ stress direction when the initial vertical stress is the minimum in situ stress. Compared with the case where the initial vertical stress is the maximum in situ stress, when the initial vertical stress is the minimum in situ stress, the vertical stress decreases faster from the roadway surface to the depth of the surrounding rock.

The horizontal displacement of the left and right sides of the survey line was extracted and curves were drawn, as shown in Figure 5. When the initial vertical stress is the maximum in situ stress, the horizontal deformation decreases rapidly from the roadway surface to the deep surrounding rock. Surrounding rock of roadway is excavated along minimum in situ stress direction of horizontal deformation degree which is higher than the tunneling of the intermediate principal stress, and hydrostatic pressure is bigger than the horizontal deformation of roadway under the conditions of the first two types of in situ stress distribution. It is important to note that the roadway is excavated along the middle ground stress direction, horizontal smaller range of compression zone. When the initial vertical stress is the minimum in situ stress, the decrease rate of horizontal deformation from the roadway surface to the 

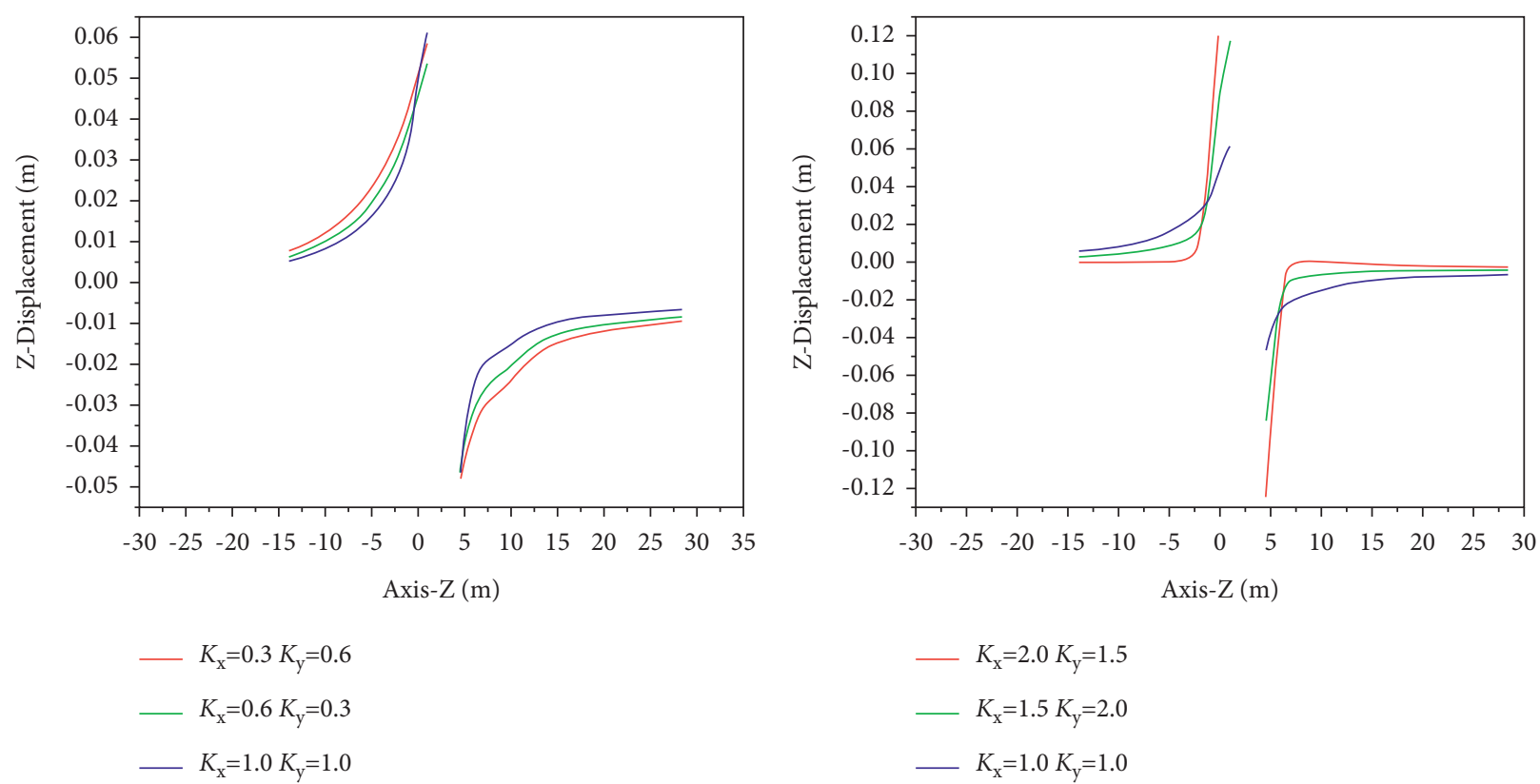

(a)

(b)

FIGURE 4: Influence of in situ stress on vertical displacement curve of roadway surrounding rock: (a) the vertical stress is the maximum principal stress; (b) the vertical stress is the minimum principal stress.

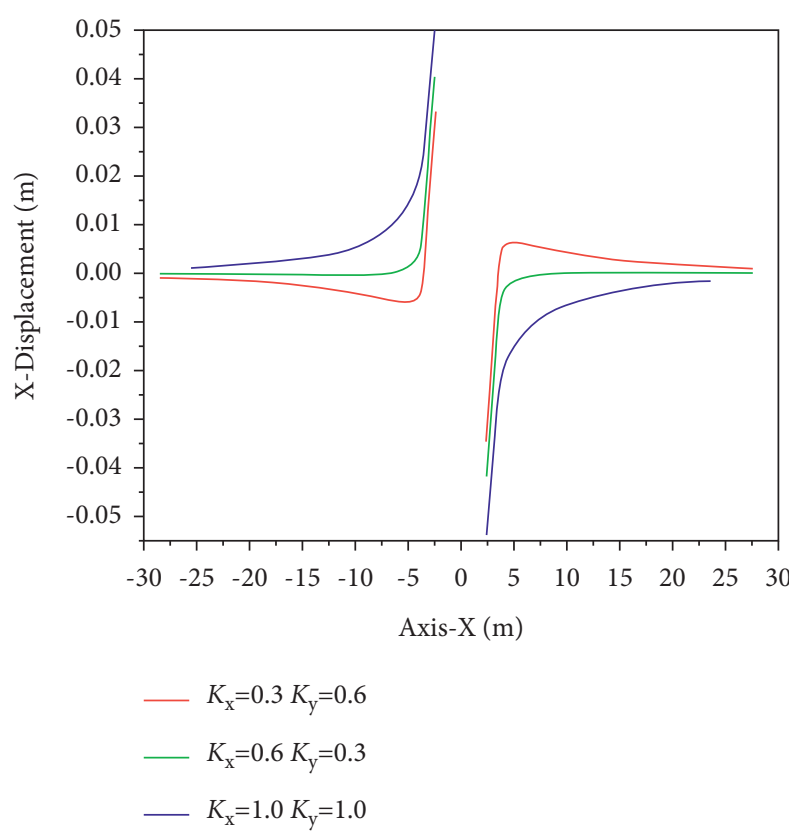

(a)

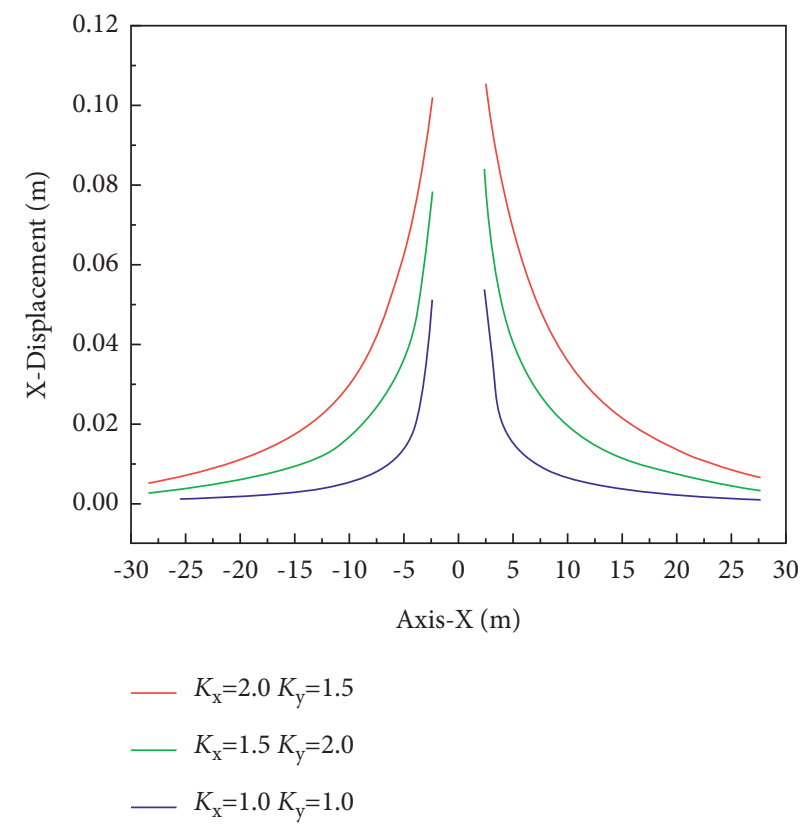

(b)

FIGURE 5: Influence of in situ stress on horizontal displacement curve of roadway surrounding rock: (a) the vertical stress is the maximum principal stress; (b) rhe vertical stress is the minimum principal stress.

deep surrounding rock is significantly less than that of the initial vertical stress which is the maximum in situ stress. The horizontal deformation of the tunnel is obviously higher than that of the tunnel with the maximum ground stress. According to the geological conditions, the rock strata have an inclination angle of $15^{\circ}$, which leads to the different gravity of the overlying rock strata at the positions of the two sides of the roadway after excavation. Therefore, the stress redistribution process is not symmetrical. However, according to the influence curve of ground stress on the 

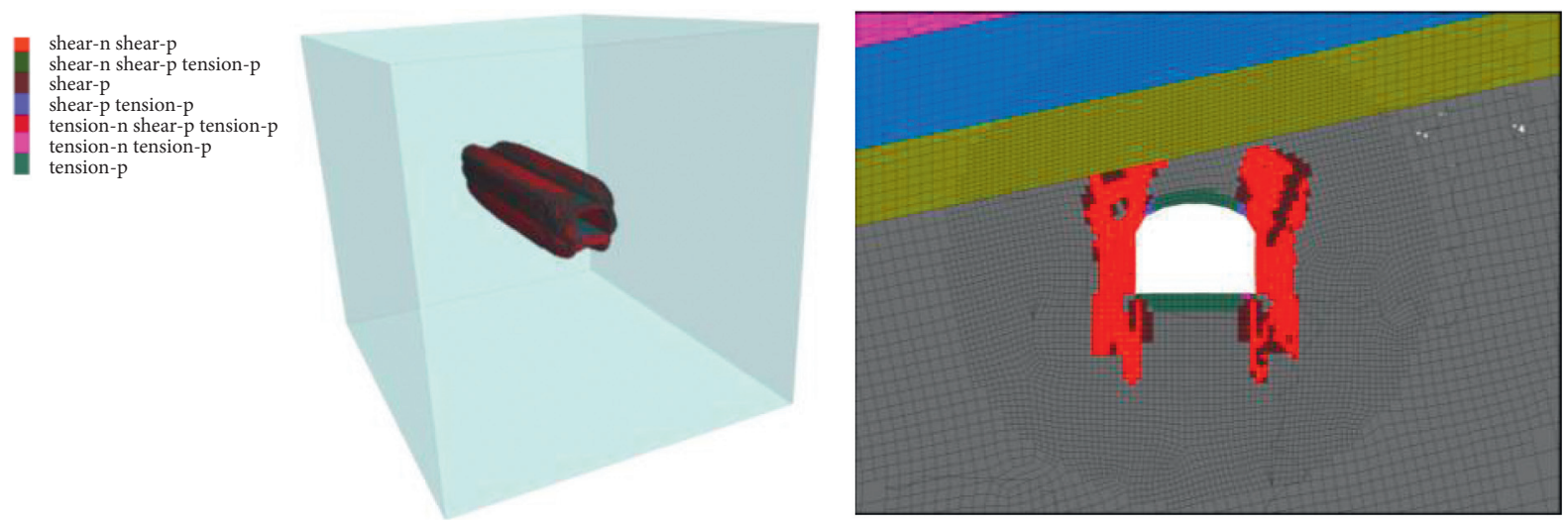

(a)

shear-n shear-p shear-n shear-p tension- $p$ shear-p

shear-p tension-p

tension- $n$ tension- $p$

tension-p
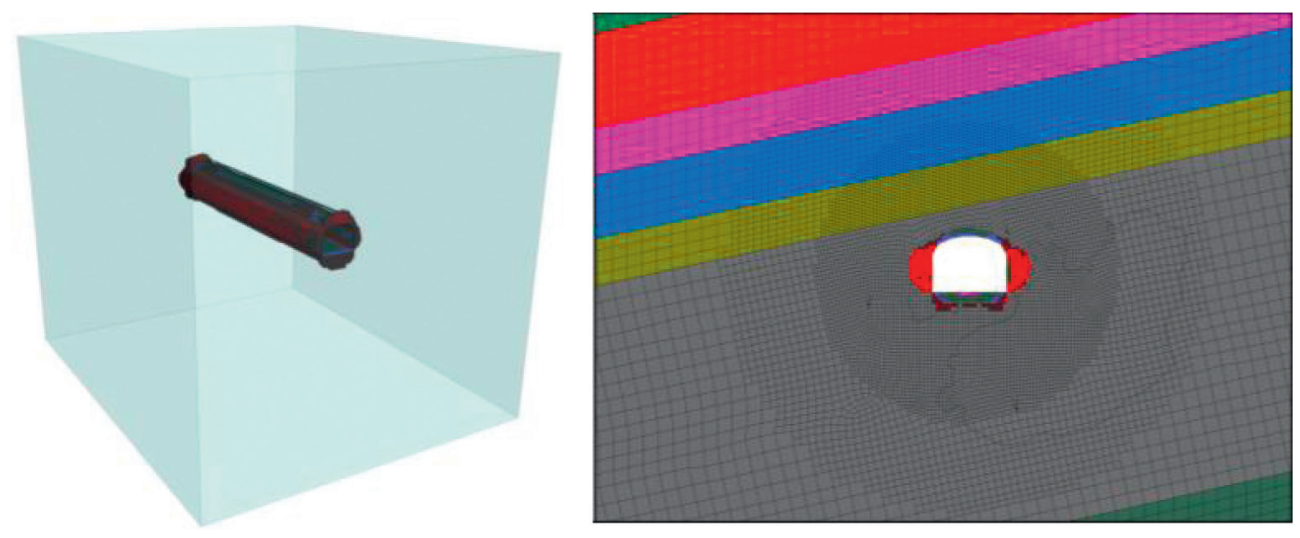

(b)

shear-n shear-p

shear-n shear-p tension-p

shear-p

hear-p tension- $\mathrm{p}$
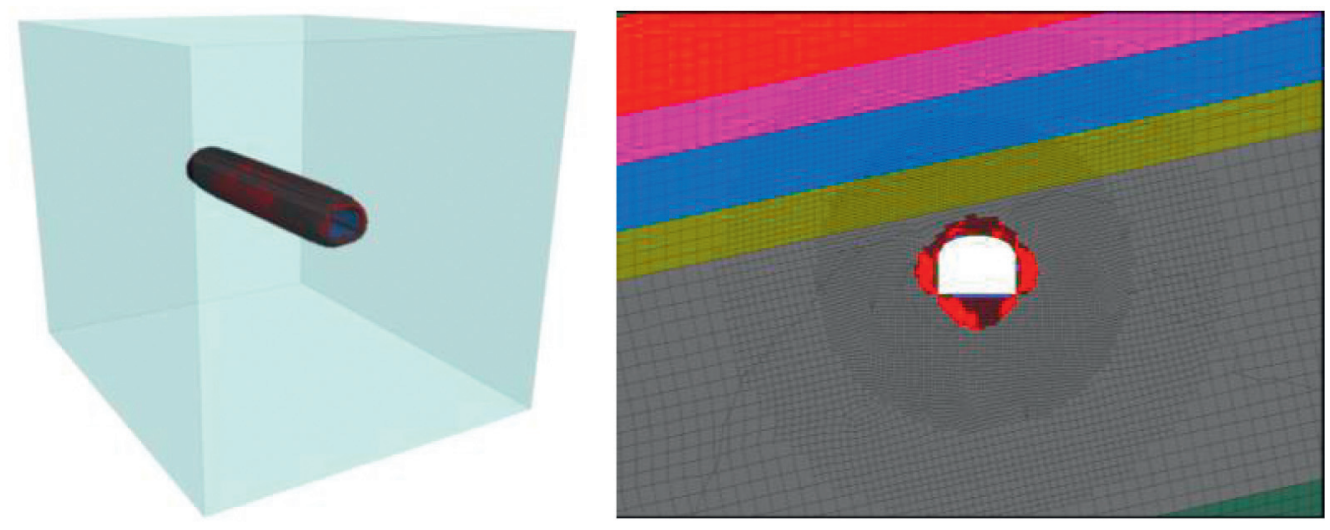

(c)

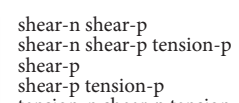

shear-p tension-p
tension-n shear-p tension-p
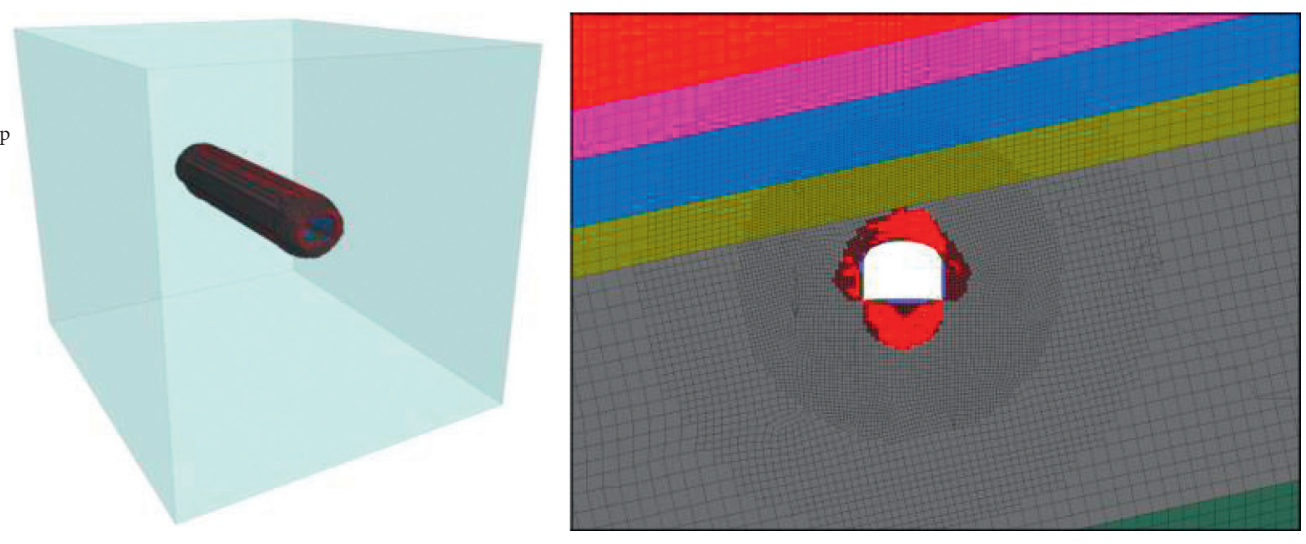

(d)

FIgURE 6: Continued. 

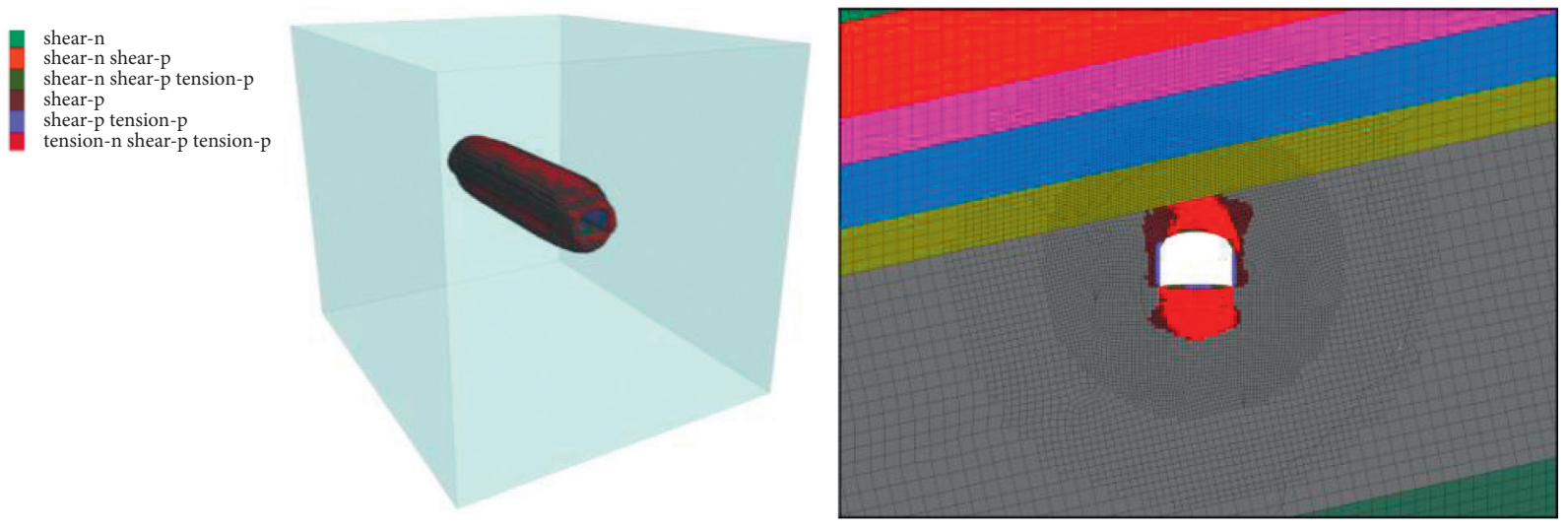

(e)

Figure 6: Influence of in situ stress on the morphology of plastic zone of roadway surrounding rock: (a) $K_{x}=0.3, K_{y}=0.6$; (b) $K_{x}=0.6$, $K_{y}=0.3$; (c) $K_{x}=1, K_{y}=1$; (d) $K_{x}=1.5, K_{y}=2.0$; (e) $K_{x}=2.0, K_{y}=1.5$.

horizontal displacement curve of surrounding rock in Figure 3, the difference between the left and right sides of the deformation displacement is small, so the support of the roadway can still adopt the symmetric support method for surrounding rock reinforcement.

3.2. Influence of In Situ Stress Distribution on Plastic Zone of Roadway Surrounding Rock. The influence of different in situ stress distribution forms on the plastic zone of roadway surrounding rock is shown in Figure 6. Under the condition that the initial vertical stress is the maximum in-situ stress, when the roadway is extracted along the middle insitu stress direction, the failure zone of the surrounding rock is mainly concentrated on the two sides of the roadway and expands to four shoulder angles at the same time. The failure of surrounding rock only occurs on the roadway surface of the roof and floor, and the failure range is obviously smaller than that of the two sides of the roadway. The failure zone of the two sides extends to the interface between mudstone and upper siltstone and stops expanding. When the roadway was tunneling along the direction of the minimum in situ stress, the plastic zone of the surrounding rock mainly developed on the two sides of the roadway and no longer expanded to the four shoulder angles of the roadway. The plastic zone of the surrounding rock of the roof and floor was similar to that of the roadway tunneling along the direction of the intermediate principal stress but only developed in the surface rock. Compared with the roadway tunneling along the intermediate principal stress direction, the failure range of surrounding rock of the roadway is obviously reduced, and the spatial distribution of the roadway is contracted to the two sides of the roadway. Under the condition of hydrostatic pressure, the plastic zone of surrounding rock around the roadway basically presents uniform distribution. Compared with the previous two types of in situ stress distribution, the range of plastic zone of surrounding rock on both sides of the roadway decreases, while the range of plastic zone of surrounding rock on the roof and floor increases.
When the initial vertical stress is the minimum in situ stress and the roadway is excavated along the direction of maximum in situ stress, the failure range of surrounding rock of the roadway roof and floor is slightly larger than that of the roadway sides, but the failure area of surrounding rock still presents uniform distribution characteristics. When the roadway is extracted along the middle stress direction, the failure phenomenon of the two sides of the roadway only appears in the shallow surrounding rock. The failure zone is mainly concentrated in the roof and floor surrounding rock of the roadway, and the roof failure zone stops developing at the boundary of mudstone and upper siltstone. Compared with the roadway extracting along the direction of maximum in-situ stress, the failure area of surrounding rock on both sides of the roadway is significantly contracted, and the failure area of surrounding rock on top and bottom is expanded. Compared with hydrostatic pressure conditions, the latter two types of in situ stress lead to lower damage degree of surrounding rock on both sides of roadway and higher damage degree of surrounding rock on roof and floor.

The in situ stress distribution not only has a significant influence on the spatial failure modes of surrounding rock but also leads to significant differences in the range of plastic zones. In order to quantitatively analyze the failure range of surrounding rock, the total volume of failure units was calculated by accumulating the failure units, and a histogram was drawn, as shown in Figure 7. It can be seen from the figure that when the initial vertical stress is the maximum in situ stress, the plastic zone of surrounding rock when the roadway was tunneled along the middle in situ stress is significantly larger than that when the roadway was tunneled along the minimum in situ stress. When the initial vertical stress is the minimum in situ stress, the range of surrounding rock plastic zone when the roadway is driven along the middle in situ stress direction is slightly higher than that along the maximum in situ stress direction.

3.3. Influence of In Situ Stress Distribution on Roadway Surrounding Destruction-Danger Zone. The rock fracture 


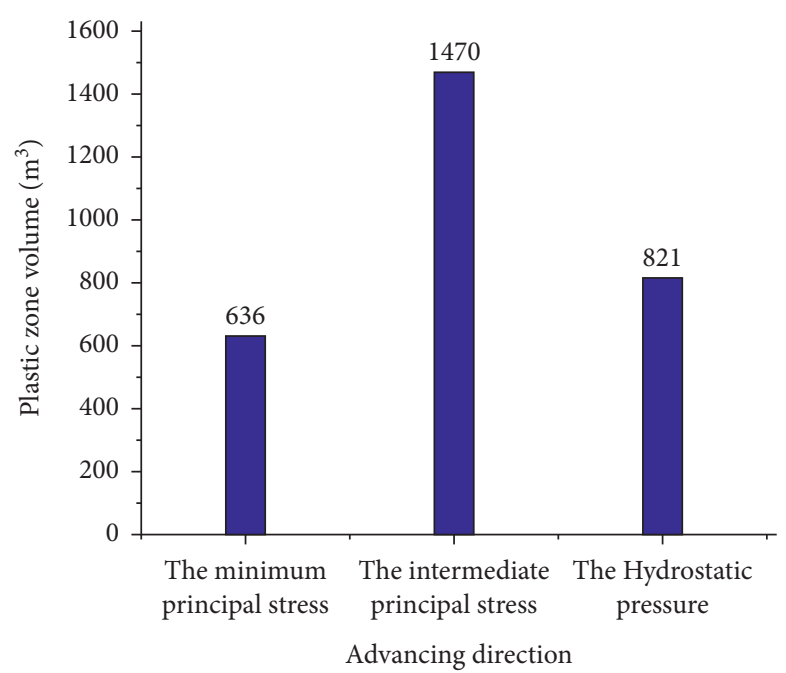

(a)

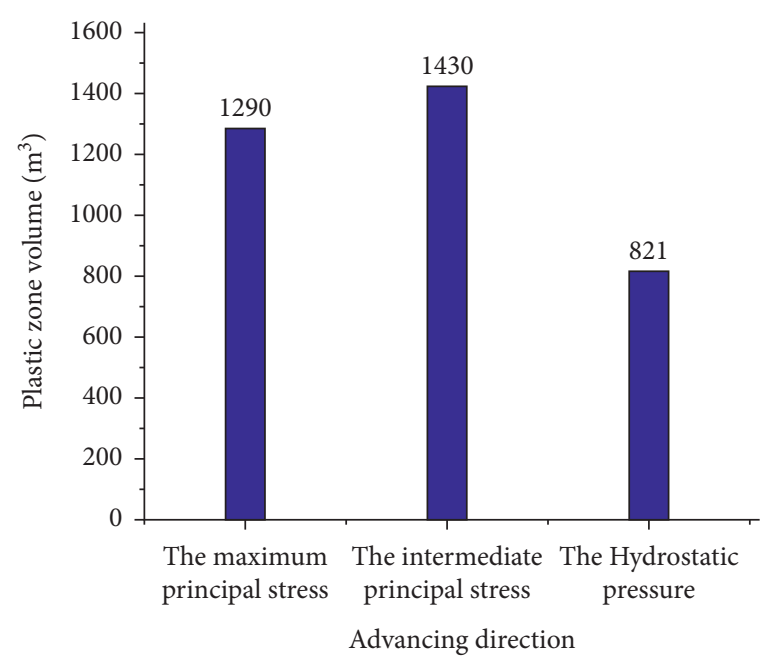

(b)

FIGURE 7: Influence of in situ stress on the range of plastic zone of roadway surrounding rock: (a) the vertical stress is the maximum principal stress; (b) the vertical stress is the minimum principal stress.

which is within the scope of the roadway destruction area grows highly, and destruction area is the key of support and reinforcement. The neighboring area is a part of the destruction rock though it is within range of the elastic state, but its mining stress environment is very bad, it is easily affected by external disturbances and enters a state of destruction, and it will become a damage zone of surrounding rock of the region. When the bolt or anchor cable support is carried out, it is necessary to pay attention to that the anchor end cannot be completely in the destruction-danger zone. Otherwise, once the destructiondanger zone enters the failure state under the external disturbance, the overall failure of the supporting structure will be caused and the reliability of roadway support will be reduced. In order to characterize the advantages and disadvantages of the stress environment in the surrounding rock of the roadway, the mining-induced stress environmental coefficient is defined as

$$
\eta=\frac{\sqrt{J_{2}}}{I_{1}}
$$

where $I_{1}$ is the first invariant of the principal stress and $J_{2}$ is the second invariant of deviatoric stress, and those can be expressed as follows:

$$
\begin{aligned}
& J_{2}=\frac{1}{2}\left(s_{1}^{2}+s_{2}^{2}+s_{3}^{2}\right), \\
& I_{1}=\sigma_{1}+\sigma_{2}+\sigma_{3},
\end{aligned}
$$

where $\sigma_{1}, \sigma_{2}$, and $\sigma_{3}$ are the maximum, intermediate, and minimum principal stresses, respectively, and $S_{1}, S_{2}$, and $S_{3}$ are maximum, intermediate, and minimum deviatoric stresses, respectively, $\sigma_{0}, S_{i}$, and $\sigma_{i}(i=1,2,3)$ are hydrostatic stress, deviatoric stress, and principal stress, respectively, and and $S_{i}=\sigma_{i}-\sigma_{0}, \sigma_{0}=I_{1} / 3$.

Since the first invariant of principal stress $I_{1}$ represents the compression degree of the surrounding rock in three directions, the larger its value is, the better the stress environment the surrounding rock is. The second invariant of deviatoric stress, $J_{2}$, represents the shear degree of surrounding rock. And the larger the value is, the worse the stress environment of surrounding rock is. And the mining stress environment factor is defined the ratio of the second invariant deviatoric stress to first principal stress invariants. Due to rock compressive shear, the greater the value of mining stress environment factor, the easier the rock mass is to be destroyed. And the rock shear strength is about $10 \%-$ $40 \%$ of rock compressive strength, so the scope of mining stress environment factor greater than 0.2 is defined as a destruction-danger zone. The spatial distribution morphology of surrounding rock in the destruction-danger zone under different in situ stress conditions was extracted, as shown in Figure 8 . When the initial vertical stress is the maximum in-ground stress, the destruction-danger zone around the roadway takes on a butterfly shape, and its range is obviously larger than that of the plastic zone. When the roadway is excavated along the direction of the middle inground stress, the destruction-danger zone has the largest range, and when the roadway is excavated along the direction of the middle in-ground stress, the destructiondanger zone presents a tendency of contraction. Under the condition of hydrostatic pressure, the destruction-danger zone around the roadway is basically uniformly distributed, and its range is slightly larger than that of the plastic zone. When the initial vertical stress is the minimum in situ stress and the roadway is excavated along the direction of the maximum in situ stress, the failure danger area is basically uniform in the two sides of the roadway and the surrounding rock of the floor, and the scope of the failure danger area in the floor increases obviously. When the roadway was excavated along the direction of the middle ground stress, the destruction-danger zone of the surrounding rock on both sides of the roadway contracted obviously, and the 


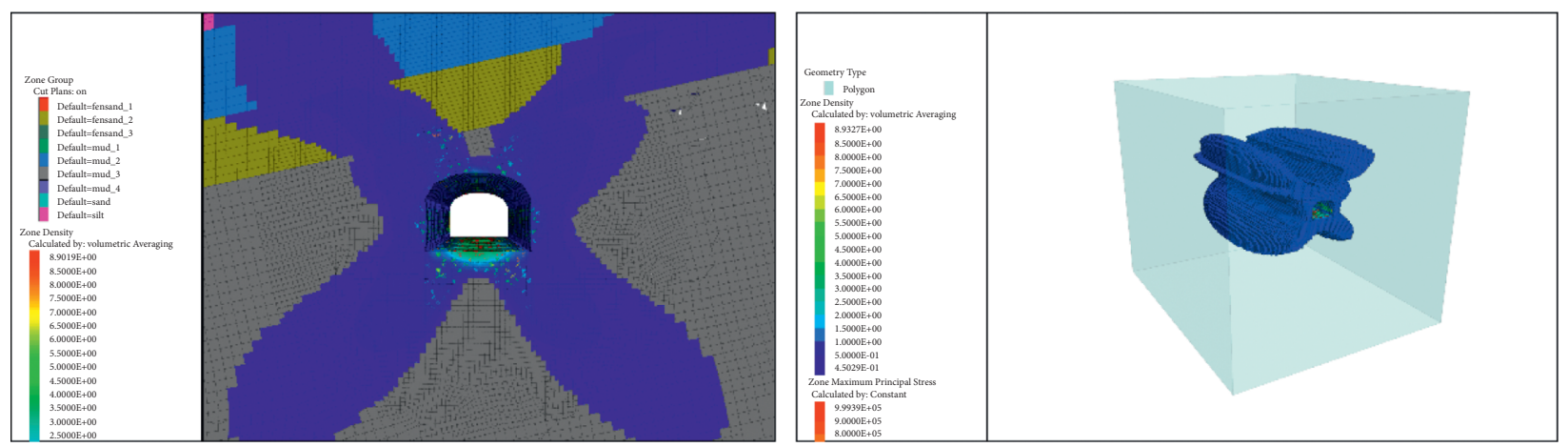

(a)

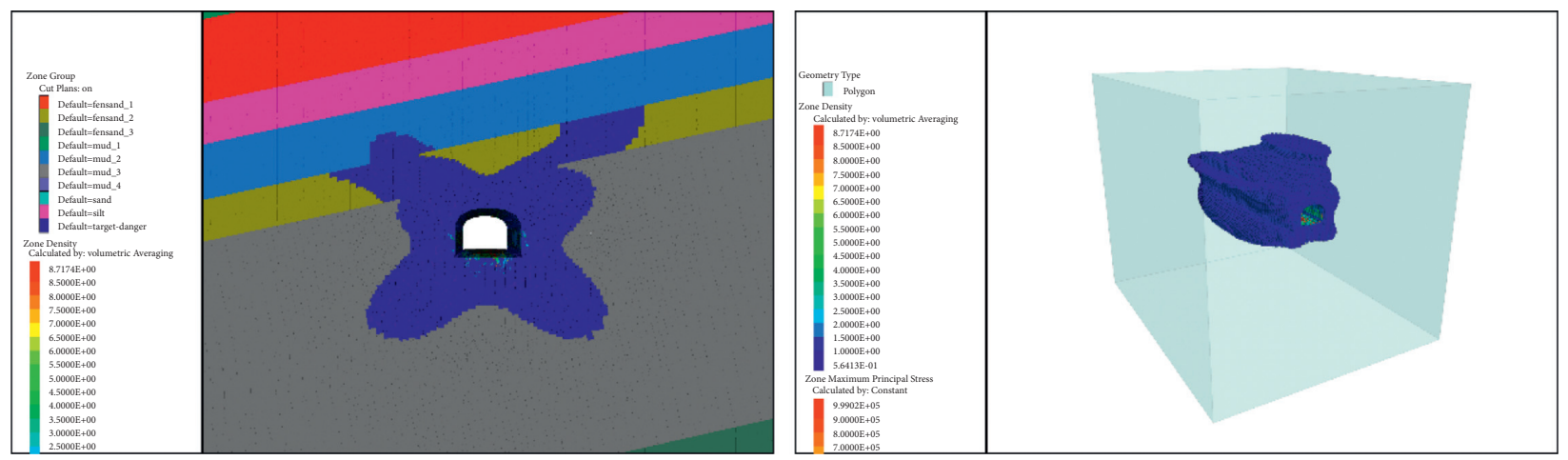

(b)
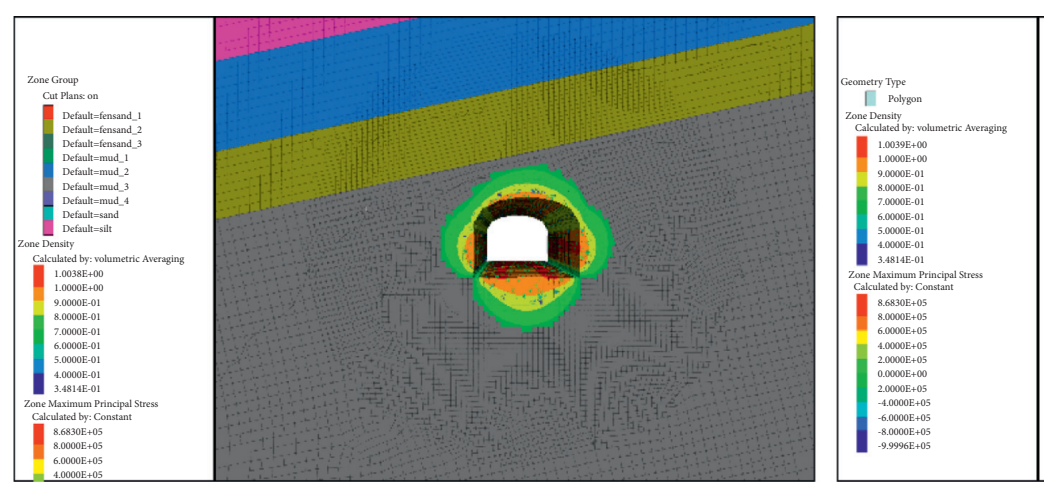

(c)
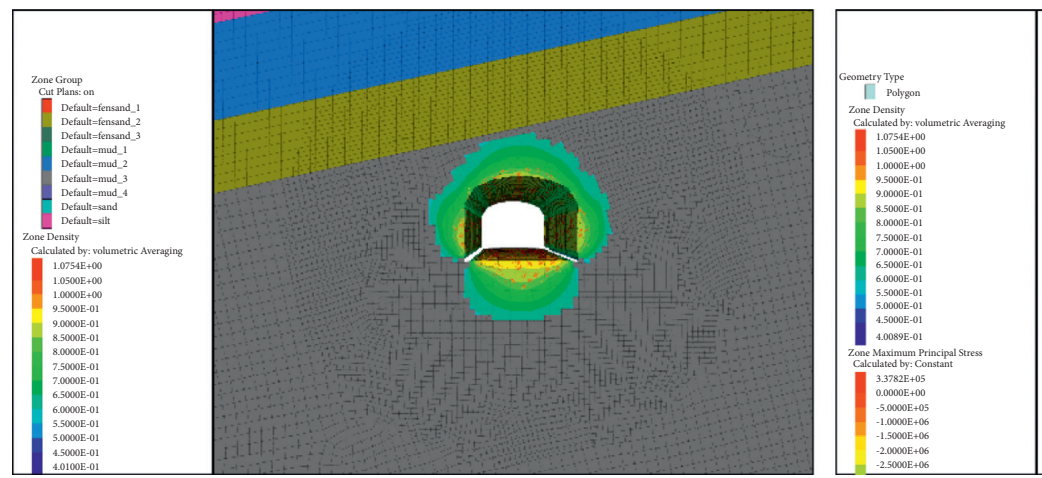

(d)

FIGURE 8: Continued. 

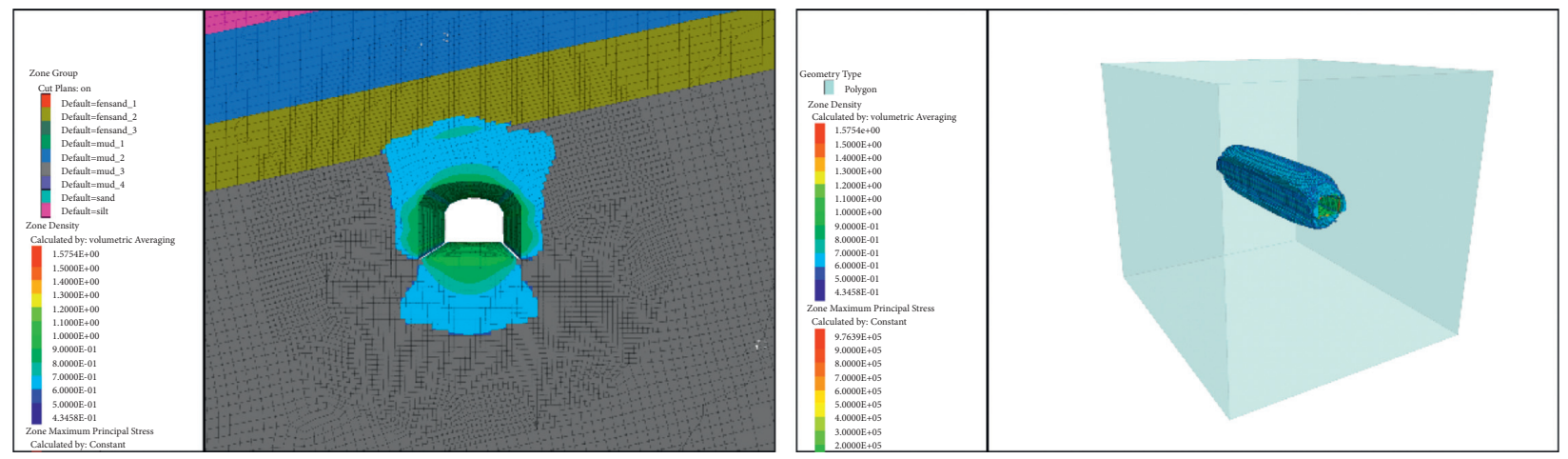

(e)

FIGURE 8: Influence of in situ stress on the morphology of destruction-danger zone of roadway surrounding rock: (a) $K_{x}=0.3, K_{y}=0.6$; (b) $K_{x}=0.6, K_{y}=0.3$; (c) $K_{x}=1, K_{y}=1$; (d) $K_{x}=1.5, K_{y}=2.0$; (e) $K_{x}=2.0, K_{y}=1.5$.

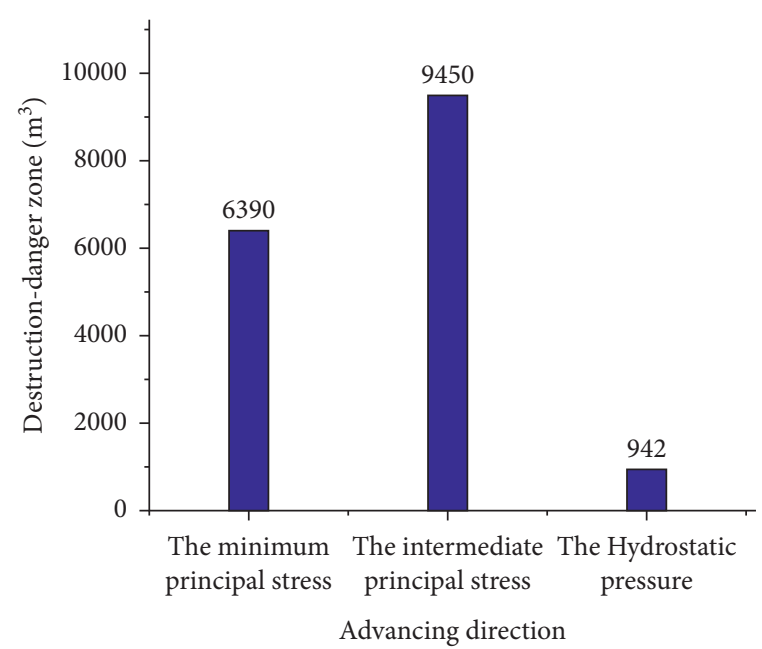

(a)

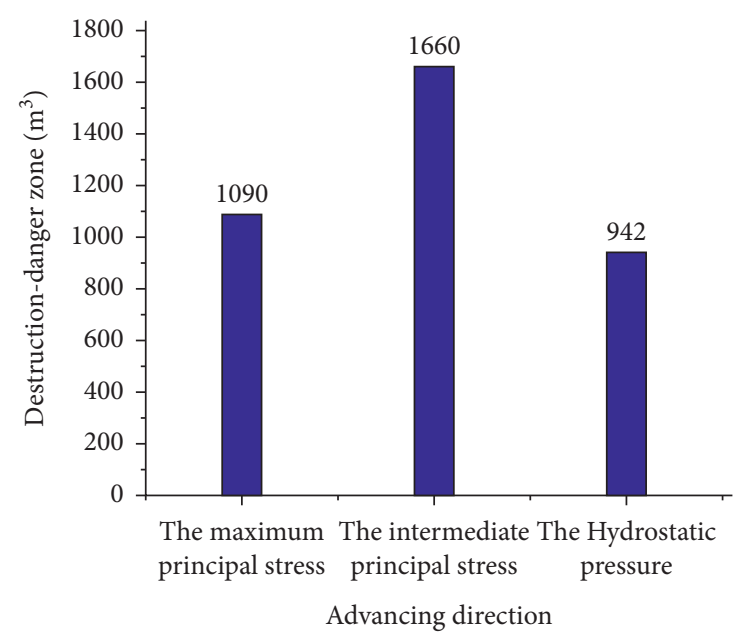

(b)

FIGURE 9: Influence of in situ stress on the failure hazard range of roadway surrounding rock: (a) the vertical stress is the maximum principal stress; (b) the vertical stress is the minimum principal stress.

destruction-danger zone of the surrounding rock on the roof and floor expanded obviously, and the spatial distribution of the destruction-danger zone was like a wine glass. Compared with the hydrostatic pressure condition, the latter two types of in situ stress lead to the increase in the uneven distribution of the failure risk zones around the roadway and the expansion of the development range.

The volume of all units within the scope of the destruction-danger zone was accumulated, and the column diagram of the destruction-danger zone range of the surrounding rock of the roadway under different in-ground stress distribution was obtained, as shown in Figure 9. Under the condition of hydrostatic pressure, the stress environment of surrounding rock is relatively good, and the range of failure danger of surrounding rock is obviously smaller than the other four types of in situ stress distribution. When the initial vertical stress is the maximum in situ stress, the range of destruction-danger zone is higher when the roadway is tunneling along the middle in situ stress direction than when the roadway is tunneling along the minimum principal stress direction. When the initial vertical stress is the minimum in situ stress, the range of surrounding rock destruction-danger zone is higher when the roadway is tunneling along the middle in situ stress direction than when the roadway is tunneling along the maximum in situ stress direction.

\section{Conclusion}

(1) When the initial vertical stress is the maximum in situ stress, the roof subsidence and floor bulge of the roadway are significantly greater than those when the initial vertical stress is the minimum in situ stress, but the displacement of the two sides of the roadway is significantly higher than that when the initial vertical stress is the minimum in situ stress.

(2) When the initial vertical stress is the maximum in situ stress, the range of plastic zone of surrounding rock is significantly higher than that of the minimum principal stress when the roadway is excavated along the direction of intermediate principal stress. When 
the initial vertical stress is the minimum in situ stress and the roadway advances along the direction of the maximum in situ stress, the scope of the plastic zone around the roadway is slightly smaller than that along the direction of the middle in situ stress.

(3) In order to characterize the advantages and disadvantages of the stress environment in the surrounding rock of the roadway, the environmental coefficient of mining-induced stress is defined. The larger the environmental coefficient of mining-induced stress is, the larger the surrounding rock stress environment is. The range of this coefficient greater than 0.2 is defined as the destruction-danger zone.

\section{Data Availability}

The data used to support the findings of this study are included within the article.

\section{Conflicts of Interest}

The authors declare that they have no conflicts of interest.

\section{Acknowledgments}

This work was financially supported by National Natural Science Foundation of China (Grant no. 51934008) and Natural Science Foundation of Heilongjiang (Grant no. LH2021E104).

\section{References}

[1] M. C. He and Q. H. Qian, Fundamentals of Deep Rock Mechanics, Science Press, Beijing, China, 2010.

[2] J. C Wang, Mining Theory and Technology of Thick Coal Seam, Metallurgical Industry Press, Beijing, China, 2009.

[3] F. Gao, Research on In-Situ Stress Distribution Law and its Effect on the Stability of Roadway Surrounding Rock, China University of Mining and Technology, Xuzhou, China, 2009.

[4] J. C Wang and Q. Fu, "Theory and application of granular medium flow in top coal emission from fully mechanized coal caving in low position," Journal of China Coal Society, vol. 27, pp. 337-340, 2002.

[5] J. L. Lu, Soft Rock Roadway Support Technology, Jilin Science and Technology Press, Changchun, China, 1995.

[6] S. R. Ning, H. Su, and J. Gao, "Research on automatic section precision forming of boom-type roadheader," in Proceedings of the International Conference on Intelligent Systems Research and Mechatronics Engineering, pp. 1250-1256, Zhengzhou, China, April 2015.

[7] Y. P. Cheng and X. L. Zhang, "Environmental impact of coal mine methane emissions and responding strategies in China," International Journal of Greenhous Gas Control, vol. 5, no. 1, pp. 157-166, 2010.

[8] J. Yuan and I. Naruse, "Effects of air dilution on highly preheated air combustion in a regenerative furnace," Energy \& Fuels, vol. 13, no. 1, pp. 99-104, 1999.

[9] Q. X. Huang and Y. W. Liu, "Limit self-stabilizing balanced arch theory of roadway surrounding rock support," Journal of Mining and Safety Engineering, vol. 31, pp. 354-358, 2014.
[10] N. J. Ma, Z. Q. Zhao, and J. C. Feng, "Supporting technology of tunnel butting long bolt under difficult condition," Coal Science and Technology, vol. 41, pp. 117-121, 2013.

[11] N. J. Ma, X. D. Zhao, and Z. Q. Zhao, "Stability analysis and control of roof in deep mining roadway," Journal of China Coal Society, vol. 40, pp. 2287-2295, 2015.

[12] M. C. He and Z. B. Guo, "Mechanical characteristics and engineering application of transversely resistant large deformation anchor bolt," Chinese Journal of Rock Mechanics and Engineering, vol. 33, pp. 1297-1308, 2014.

[13] J. C. Wang, L. Wang, and Y. Guo, "Determination of support resistance based on roof and coal wall control," Journal of China Coal Society, vol. 39, pp. 1619-1624, 2014.

[14] Y. Guglielmi, P. Cook, and F. Soom, "In situ continuous monitoring of borehole displacements induced by stimulated hydrofracture growth," Geophysical Research Letters, vol. 48, 2021.

[15] A. V. Azarov and A. V. Patutin, "Investigation of hydraulic fracture growth near a mine opening," Conference Series: Earth and Environmental Science, vol. 773, 2021.

[16] D. Pymonenko, "Influence of paleodislocation intensity and modern movements on the stressed state of massif," Web of Conferences, vol. 168, 2020.

[17] H. W. Jing, J. Y. Wu, Q. Yin, and K. Wang, "Deformation and failure characteristics of anchorage structure of surrounding rock in deep roadway," International Journal of Mining Science and Technology, vol. 30, pp. 593-604, 2020.

[18] G. Masoud, S. Korosh, S. Mostafa, and M. Reza, “A critical review on the developments of rock support systems in high stress ground conditions," International Journal of Mining Science and Technology, vol. 30, pp. 555-572, 2020.

[19] H. B. Wen and Y. Q. Li, "Study on stress distribution law and stress performance characteristics of multiple data mining for harbour portal crane detection," IOP Conference Series: Earth and Environmental Science, vol. 631, Article ID 012039, 2021.

[20] D. Priyan and J. Paul, "What is the body of knowledge for engineers involved with civil engineering systems? - a 2020 vision," Civil Engineering and Environmental Systems, vol. 37, Article ID 1858065, 2020.

[21] G. T. Masterton.Gordon and J. Paul, "Integrating the liberal arts into the body of knowledge for civil engineering systems engineers," Civil Engineering and Environmental Systems, vol. 37, Article ID 1832086, 2020.

[22] W. Jowitt Paul, "Systems and sustainability," Civil Engineering and Environmental Systems, vol. 37, Article ID 1839892, 2020.

[23] K. Daniel and P. Frederick, "Shealy.tripp et al,"recognizing differences in underrepresented civil engineering students' career satisfaction expectations and college experiences"," Journal of Management in Engineering, vol. 37, 2021.

[24] M. Dag, "Review of turbulence in coastal and civil engineering by B. Mutlu Sumer and David R. Fuhrman," Journal of Waterway, Port, Coastal, and Ocean Engineering, vol. 147, 2021.

[25] V. Sorin, M. Marin, and D. Ovidiu, "Vibration properties of a concrete structure with symmetries used in civil engineering," Symmetry, vol. 13, p. 656, 2021.

[26] D. Z Kong, S. J Pu, Z. H. Cheng, G. Y. Wu, and Y. Liu, "Coordinated deformation mechanism of the top coal and filling body of gob-side entry retaining in a fully mechanized caving face," International Journal of Geomechanics, vol. 21, 2021.

[27] D.-Z. Kong, Z.-B. Cheng, and S.-S. Zheng, "Study on the failure mechanism and stability control measures in a largecutting-height coal mining face with a deep-buried seam," Bulletin of Engineering Geology and the Environment, vol. 78, no. 8, pp. 6143-6157, 2019. 
[28] J. Lou, F. Gao, J. Yang et al., "Characteristics of evolution of mining-induced stress field in the longwall panel: insights from physical modeling," International Journal of Coal Science \& Technology, 2021.

[29] W. Jiachen, W. Weijie, and Z. Jinwang, "Theoretical description of drawing body shape in an inclined seam with longwall top coal caving mining," International Journal of Coal Science \& Technology, vol. 7, no. 1, pp. 182-195, 2020.

[30] J. Wang, S. Yang, W. Wei et al., "Drawing mechanisms for top coal in longwall top coal caving (LTCC): a review of two decades of literature," International Journal of Coal Science \& Technology, 2021. 